\title{
Mental health care in Spain
}

\author{
Francisco Torres-González
}

Spain is a member state of the European Union, covering over $500,000 \mathrm{~km}^{2}$ and with a population of more than $\mathbf{4 0}$ million. However, taking into account only the gross national product, there is no doubt that Spain still belongs to the southern countries.

Spain has a homogeneous population, from an ethnological, cultural and religious point of view. The country is divided into 17 'Autonomous Communities' or regions, some of which have their own language. They have different degrees of administrattve autonomy; Andalusia, Catalonia, the Basque Country, and Galicia are those which have local governments with the highest level of independence. Consequently, they are able to run fully autonomous regional health services.

\section{Spanish poychiatric reform 1}

The new cultural winds of the late ' $60 \mathrm{~s}$, including the anti-psychiatry movement, and the proximity to the end of Franco's regime. created the framework for numerous battles against closed institutions, from 1970 to 1975. Famous cases were those of the Oviedo Psychiatric Hospital, the Mental Institute of La Santa Cruz, and the Psychiatric Sanatorium of Conxo.

After Franco's death in 1975, and until 1978, Spain dedicated itself to political transition to a modern democracy. The first local electoral polls were held in 1979. Some of the new democratic local councils decided to give priority to the reform of their psychiatric institutions. Shortly afterwards, some regional governments of the newborn autonomous communities began taking over the leadership of the process.

Meanwhile, a wide debate started among professionals, policy makers, users and the population as a whole. This led to an international conference on mental health in 1983, organised by the World Health Organization Regional Office, providing a framework for criterla on which to base a national plan. A Ministerial Commission for Psychiatric Reform was set up in 1984/85
(Ministerio de Sanidad y Consumo, 1985). It was launched at a very opportune moment when many initiatives of different orientation were starting to flower throughout the country. Simultaneously, a new law was being formulated by the Ministry, where many of the Commission's recommendations found a place. The report was mainly inspired by the community psychiatry model, and was based on the principle of comprehenstveness. It was brief and the recommendations precise. It immediately gained strong support among professionals and institutions, and has become the theoretical reference for many plans and documents since.

\section{The structure of the mental health care subsystem}

The Spanish Health System was first brought into creation by the 1986 General Law on Health $^{2}$. The system includes all the regional health services of the 17 autonomous communities, which are run by different local governments. Although it is mainly based on public services, private health companies have their own complementary place.

It should be said, however, that the mental health care subsystem is by no means homogeneous through all Spain. Some regions today offer a modern network of community mental health services ${ }^{3}$, while others are still based on the traditional psychiatric hospital.

\section{Psychiatric beds}

Spanish rates for both psychiatric beds and psychiatric hospitalisation were traditionally inferior to Northern European standards. In addition to a low baseline the rates, as everywhere else, had been dropping for the last 25 years. Furthermore, the 1985 Ministerial Commission recommended the active reduction of the number of beds in psychiatric hospitals. 
Table 1. Reduction of the number of beds in Andalusian psychiatric hospltals over the last ten years

\begin{tabular}{lllll}
\hline Year & Short-stay beds & \multicolumn{2}{c}{ Long-stoy beds } & Total number of hosplitals \\
\cline { 3 - 5 } & & Retionded \& geriatic & Chronic poychotics & \\
\hline 1985 & 480 & 1.506 & 1.137 & 8 \\
1994 & 0 & 660 & 376 & 5 \\
\hline
\end{tabular}

Table 2. Increase in number of psychiatric units and beds at Andalusian general hospltals over the last ten years

\begin{tabular}{llll}
\hline Year & $\begin{array}{l}\text { Number of } \\
\text { units }\end{array}$ & $\begin{array}{l}\text { Number of } \\
\text { beds }\end{array}$ & Rotio/10,000 \\
\hline 1985 & 3 & 104 & 0.16 \\
1994 & 18 & 480 & 0.68 \\
\hline
\end{tabular}

As pointed out, it is difficult to speak of a homogeneous structural development of psychiatric services for Spain as a whole. Active programmes of completely closing down all psychiatric hospitals are being carried out by the local government of Andalusia ${ }^{4}$ in the south, and Asturias in the north, but in very few other places.

Let us take the example of Andalusia. It is the second biggest region ${ }^{5}$ in Spain, and one of the poorest. Andalusia has perhaps been where the health authorities have shown a more decisive policy of closing down traditional psychiatric hospitals. The results of that policy may be seen in Table 1 . It is necessary to point out that several of the remaining psychiatric hospitals within the health system (total 376 beds) are nowadays merely long-stay wards. None of them retains the status of an independent hospital; on the contrary, they are attached, not physically but administratively. to a general hospital. In addition, the management of about 600 beds, and the buildings where they are located, have been transferred to the Andalusian social service system, and the status has been changed to nursing homes for old psychiatric patients.

That policy would not have been possible without other complementary active policies. The most important one has been the progressive re-direction to general hospitals of psychiatric acute admissions. In fact, since January 1992, there is not a single acute bed in any of the remaining Andalusian psychiatric hospitals. The reduction of the number of psychiatric beds has also been made possible by the development of active communitybased rehabilitation programmes, community care, alternative accommodations, and so on. Nevertheless, the pace of these alternative programmes, is seen as being too slow by many professionals. Finally, although not the least important contribution, the Andalusian Institute for Social Services has progresstvely taken into its own institutions many aged and adult mentally retarded people who were in long-stay wards at psychiatric hospitals.

In 1991, there were 2,162 beds in 91 units in general hospitals in Spain and 1,815 short stay beds in 54 units located in psychiatric hospitals. Since 1992, psychiatric units within general hospitals have taken on $100 \%$ of the demand for psychiatric treatment in public hospitals in Andalusia. Despite the noticeable increase in both the number of beds and the number of general hospitals with psychiatric units, the ratio of acute beds/population (0.68) in Andalusia is still comparatively low. However, during 1993, the admission/10,000 rate of these beds has been only 10.68 , and the occupation rate $78.6 \%$. Certainly, the mean of the length of stay ( 18.61 days) is much shorter than, for instance, the British standard.

Staff at these units usually work with the following three programmes:

management and treatment of both new and chronic patients on a short-stay basis

psychiatric case management on the emergency ward

consultation on psychiatric patients and mental health problems with other hospital units and services.

\section{Role of the primary health care level}

People in Spain and Andalusia use the family doctor as a doorway to the health system. This 'cultural' behaviour is the same in other European countries where most patients follow a pathway directly from the community to their general practitioner and from there straight to psychiatric services (Gater et al, 
1991). This is in accordance with the proposed model: the primary health care level should be the backbone of the health system, and, specifically, where more than $85 \%$ of mental health problems should be dealt with.

In reality, however, things are different. Despite Spain having one of the highest rates of doctors per capita in Europe, and despite the theoretical model proposed by the General Law on Health, the 'filters' based on the family doctor, brilliantly described by Goldberg \& Huxley (1980), do not work. This means that psychiatric services are overloaded with too many consultations, and makes the mental health care subsystem as a whole very inefficient, regardless of the high number of psychiatrists available.

\section{Community-based psychiatric services}

There are 70 so-called mental health district teams (MHDTs) and 11 community-based child and adolescent mental health units (CAMHU) to cover Andalusia. The MHDTs are composed of a varying number of personnel, depending on the size of the population to be covered. However, all teams have at least a psychiatrist, a psychologist, a social worker, a nurse, an assistant nurse, and a clerk. All teams are installed at primary health care centres, sharing facilities with family doctors and their teams, i.e. there are no health centres exclusively for psychiatric patients, nor psychiatric out-patient clinics in buildings of their own. The majority of these units were set up in 1987-88, and experience is showing them to be more and more overloaded by very high demand for consultations.

If we take the smallest sanitary rural district of Andalusia, we can see that a fairly small team (one psychiatrist and one psychologist, plus other members as described above) gave specialised consultations to 387 new patients in a year. This works out to a yearly ratio of 103 new cases/10,000 inhabitants. Total consultations in the year were 2,900. Similar rates can be found if we take a standard urban zone, let us say 'Granada South' district, with a population of 200,000 , attended by approximately 20 professionals, seven of them psychiatrists and psychologists, plus a variable number of junior doctors and psychologists in training. In this case the ratio of new cases per 10,000 was 101, and the total number of consultations was almost 12,000 (1993 data for both districts).
The child and adolescent mental health units operate as supporting resources to the mental health district teams, and to other educational and sanitary groups.

\section{The 'old and the new' problems}

Some of the 'old problems' were stated in an WHO report on the Spanish experience (World Health Organization, 1988).

\section{Lack of reliable data}

The continuing "lack of reliable data for proper planning and evaluation ..." does not allow reliable observation and measurement of the processes that have taken place in many of the 17 Autonomous Communities. No reliable comprehensive information is published which might allow us to answer whether the 'factors' have changed very much since 1986. However, some things may be asserted.

\section{Financing and pacing}

Increases in financing have been moderate throughout Spain. Advances have been more noteworthy in a few of the Autonomous Communities, principally from 1986 to 1989.

The pace of implementation of the new primary health care model has been very irregular and has changed from one region to another and from one year to the next. From 1985 to 1994 , a situation has been reached where $65-70 \%$ of the population is covered by the new model.

\section{Staffing}

Geographical differences are again great. Generally speaking, the psychiatrist rate is satisfactory. In a recent multicentre study, the Spanish centre involved, Granada, with 62 "psychiatrists per million at risk", showed the highest rate of all (Gater et al, 1991). Geographical distribution is uneven, however. Networks of equitable territorial services have been developed by some regions, such as Andalusia and Asturias, while it is possible to find urban concentrations in others.

Again, Andalusia and Asturias were the first regions to introduce in 1988 a training programme specifically addressed to psychologists. The central government did the same for the whole of the country in 1994. However, clinical psychology is not yet an official speciality approved by Spanish academic authorities. 
There is no approved speciality for psychiatric nursing either, which means problems of inability to cope with specific problems of psychiatric patients. In addition. psychiatric community nursing is insufficient in the leading regions and virtually nonexistent outside them.

The lack of well trained psychiatric nursing staff, together with the insufficient filtering role of family doctors, are the two truly great problems of the mental health care subsystem in Spain.

\section{Other community resources}

As stated in the WHO report, the scarcity of community resources has been an important factor in the prevention of mental health problems. This has traditionally been true of Spain due to the underdevelopment of the country. Fortunately, this situation has changed thanks to the good economic decade of the $80 \mathrm{~s}$ and public effort. Nowadays, Spanish community resources, especially in poorer regions, are still far from that of Northern European countries but they are even farther from the level of ten years ago.

The 'new problems' are due in part to the process of full integration of the mental health subsystem into the general health system which is not being achieved without losses.

\section{Loss of specificity}

A general hospital, like any other institution, tries to simplify complexdty, and to homogenise diversity. However, the care of psychiatric patients involves different needs, which cannot be homogenised, nor assumed, by a general hospital. The way patients dress can be taken as an example: in a general hospital, every patient must wear pyjamas but this is not the case with psychiatric patients. The hospital laundry therefore frequently finds it difficult to manage the normal clothes psychiatric patients ordinarily wear.

\section{Lack of sensitivity for the chronic psychotic patient}

The chronic psychotic patient is at risk of being at the losing end. Often rehabilitation programmes do not recetve enough support from managers, or it is difficult to develop alternative accommodation and occupational programmes which slows down the implementation of community care programmes.

\section{The aggressive patient}

The psychiatric hospital used to cope with this problem. Active delusional patients, who need prolonged compulsory treatment, do not always fit smoothly within the new types of service. This situation may create growing negative publicity against the nature and aims of the reform.

\section{The future and cost of the subsystem}

Questions as to whether it is more or less expensive than the previous model have not been answered. Moreover, the cost of the transitional steps have not been properly evaluated. Furthermore, there is also uncertainty as the psychiatric reforms have been introduced while the health system as a whole, in all European countries, is going through the deepest financial crisis since the model came into being after World War II.

\section{References}

Gater R. DE Almeida, B., BArraentos, G. et al (1991) The pathways to psychiatric care: a cross-cultural study. Psychological Medictne, 21, 761-774.

GoldBerR, D. P. \& HuxaEY, P. (1980). Mental fllness in the Community: the pathway to psychiatric care. London: Tavistock.

MINISTERo DE SANIDAD y Consumo (1985) Informe de la Comisión Mintsterial para la Reforma Psiquiditrica. Madrid: Servicto de Publicaciones.

WORLD HEALTH OranNization (1988) Mental Health Services in Southern Countries of the European Region. EURO Reports and Studies 107. Copenhagen. WHO. Regional Office for Europe.

\section{Notes}

1. Perhaps the best text related to this topic is the book edited by M. Gonzalez de Chavez: La Transformación de la Asistencia Psiquiatrica, published by the Spanish Neuropsychiatric Association. Madrid, 1980. Also the more recent work of T. Angosto (1992) La asistencla psiquiátrica en España en la última década. Chapter 7 in Lbro del año en Psiquiatria. Madrid: SANED.

2. Previously. several networks on national and local levels were operating. with a subsequent lack of coordination.

3. That is the case of Andalusla, Asturias, Navarra, and part of the Madrid region.

4. Where the 'community psychiatry' principles were stated by a Law of the Andalustan Parliament in 1984.

5. With over $90,000 \mathrm{~km}^{2}$ and more than 7 million people. Andalusta is bigger than several members of the European Union.

Francisco Torres-González, Professor, Coordinator of Mental Health Area, Granada University Hospital, 18012 Granada, Spain 